
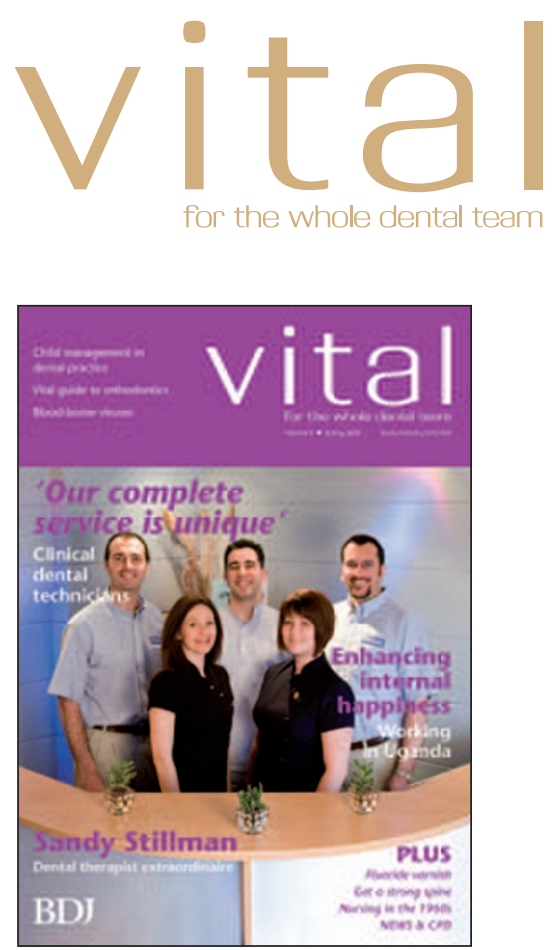

Cover feature photography by: Filskifoto Filip Gierlinski

Mobile: 07859078945

Email: filski77@hotmail.com

The cover image was taken at Pure Dentistry and The Denture Clinic in Harpenden. Huge thanks to the whole team and to Pauline, who guest-starred.

Editor-in-Chief: Stephen Hancocks OBE Editor: Kate Maynard

Production Editor: Esther McKeown Art: Sandra Murrell, Filip Gierlinski

Publisher: Kim Black-Totham

Head of Advertising: Alison Mason

Advertising enquiries: +44 (0)20 78434729

Production Controller: Ian Pope

Vital Editorial Board: Julia Brewin, Larry Browne, Kathryn Marshall, Julie Wright, Christopher Lynch, Marina Harris, Jim Mackie

British Dental Journal

The Macmillan Building

4-6 Crinan Street

London N1 9XW

Tel: + 44 (0)20 78433680

Fax: + 44 (0)20 78434725

(c) British Dental Journal 2008. All rights reserved. No part of this publication may be reproduced, stored in a retrieval system or transmitted in any form or by any means, electronic, mechanical, photocopying recording or otherwise, without the prior permission of the British Dental Journal.

The opinions expressed in this publication are those of the authors and not necessarily those of the British Dental Association or the editor. Appearance of an advertisement does not indicate BDA approval of the product or service.

\section{Dental nurses rOCK}

Kate is wondering how to remind Vital readers of the registration deadline in a new, exciting fashion.

Are you a Facebook addict yet? If you're familiar with this web phenomenon, you will know that people can create 'groups' centred round a common interest or cause, and invite friends to join and discuss. A quick search on 'dental nurse' generated a list of groups including 'I'm a dental nurse and I just can't mix a material standing up!' (38 members) and 'Dental nurses against registration' (six members) but more encouragingly 'Dental nurses rock' (581 members).

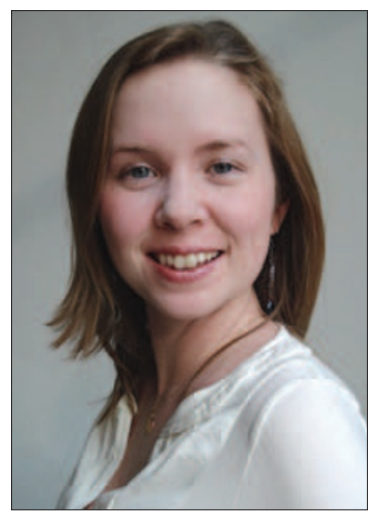

Luckily it seems the latter sentiment is shared by dental nurses across the UK, as December saw registration figures shoot up to almost 20,000. If you have yet to send off your registration form, there's still time, so go to www.gdc-uk.org, telephone 0845 222 4141, or see the last few issues of Vital for more information. The deadline is 30 July 2008 , by the way!

It is of course not only dental nurses who rock! This issue is a CDT (clinical dental technician) special. Like dental nurses, CDTs have begun registering with the GDC; read about the work this DCP group put in to get this far and about a dentist who has welcomed the change in CDT status with open arms (pages 34-37).

Vital aims to inform and entertain the whole dental team, which we hope is reflected in the variety of articles in each issue. However, you may notice that the advice section this spring is a little larger than usual. As compulsory CPD for DCPs comes into play we plan to provide as many articles as possible on the core CPD subjects, and others besides. Look out for more information on obtaining your CPD hours through Vital in the summer issue (14 June).

If there's something you would like to read about that you can't find in Vital, or if you would like to contribute - perhaps with a personal account like Cynthia Harper (page 30) - or share your views on the letters page, do get in touch. Vital is your magazine so help us to make it a VITAL read!

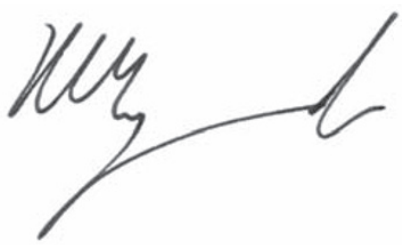

Kate Maynard, Editor k.maynard@nature.com

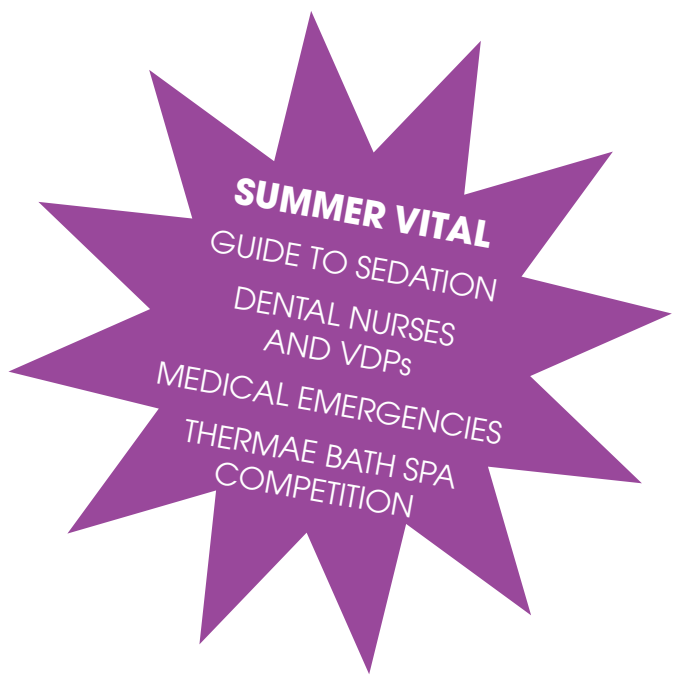

